\title{
ADSORPTIVE REMOVAL OF TRACE CONCENTRATION OF FLUORIDE FROM WATER USING CERIUM LOADED DRIED ORANGE JUICE RESIDUE
}

\author{
Hari Paudyal $^{1,2^{*}}$, Katsutoshi Inoue ${ }^{2}$ \\ ${ }^{1}$ Central Department of Chemistry, Tribhuvan University, Kirtipur Kathmandu, Nepal \\ ${ }^{2}$ Department of Applied Chemistry, Saga University, Honjo 1, Saga 840-8502, Japan \\ Corresponding author: hpaudyal@cdctu.edu.np
}

(Received: August 8, 2018; Revised: December 17, 2018; Accepted: December 20, 2018)

\begin{abstract}
Two adsorbents for fluoride ion removal were developed from dried orange juice residue (DOJR) after loading Ce(III) and Ce(IV) in this study. The characterization of adsorbents was done by an energy dispersive X-ray spectroscopy, X-ray diffraction analysis, electron microscopy and chemical analysis. The experimental results indicated that the fluoride removal efficiency of both the adsorbents was influenced significantly by $\mathrm{pH}$ and the optimum operating $\mathrm{pH}$ was found to be 4. The equilibrium data were well fitted with Langmuir isotherm model and the maximum adsorption capacity of $\mathrm{Ce}(\mathrm{III})-\mathrm{DOJR}$ and Ce(IV)-DOJR for fluoride were evaluated to be 0.67 and $1.22 \mathrm{mmol} / \mathrm{g}$, respectively. Leakage of cerium from Ce(IV)-DOJR was negligible for trace concentration of fluoride but it was significant for high concentration of fluoride at $\mathrm{pH}$ below 3 resulting fluoride precipitation. Therefore, cerium-loaded DOJR investigated in this study can be considered as an efficient, environmentally benign and promising alternative for the treatment of fluoride contaminated with trace amount of fluoride ion.
\end{abstract}

Keywords: Fluoride, Adsorption isotherm, Cerium-loaded DOJR, Fluoride precipitation, X-ray diffraction analysis

\section{INTRODUCTION}

The contamination of surface and ground water occur due to natural as well as anthropogenic processes. Naturally, the pollution of water with fluoride occurs due to weathering of fluoride rich rocks and minerals whereas anthropogenic pollution takes place by the discharge of industrial waste water generated from semiconductor, plating and other high tech industries (Shen et al. 2003). Fluoride ion concentration below $1 \mathrm{mg} / \mathrm{L}$ is considered to be beneficial for our dental health. However, consumption of high concentration of fluoride for long period of time can cause mottling of teeth and lesions of endocrine glands, liver, thyroid and other organs in addition to dental and skeletal fluorosis. It is estimated that more than 70 million people are suffering from fluorosis globally due to consumption of fluoride contaminated water (Viswanathan \& Meenakshi 2008, Paudyal et al. 2011). In order to minimize the risk, WHO has recommended the tolerance limit of $1.5 \mathrm{mg} / \mathrm{L}$ of fluoride in drinking water (WHO 1993). Therefore, it is necessary to lower the elevated amount of fluoride in water.

Nowadays, there has been a considerable increase in the prevalence of dental and skeletal fluorosis among population around the fluoride polluted area (Meenakshi \& Viswanathan 2007). Moreover, intake of fluoride from sources other than drinking water such as foodstuffs, toothpaste, fluoridated milk, dietary supplements, fluoridated salt, mouth rises and brick tea are another cause of fluorosis in our body. The highly preferable alternative for the preventive measure is to find a supply of drinking water with safe fluoride levels and one of such option is defluoridation (Liao \& Shi 2005). Most commonly used methods for defluoridation of water are chemical precipitation, membrane process, ion exchange and surface adsorption. The surface adsorption using chemically modified waste biomass material seems to be more promising because of its easy operation and affordable cost (Biswas et al. 2009, Zhao et al. 2008).

The orange juice residue obtained after juicing is one of the pectin rich biomass that can be easily converted into cation exchanger by basic hydrolysis reaction with lime water (Paudyal et al. 2013). In the present work the cattle food of orange juice residue abbreviated as dried orange juice, DOJR, was utilized for the preparation of adsorbents for fluoride by loading $\mathrm{Ce}$ (III) and $\mathrm{Ce}$ (IV). The fluoride removal potential of cerium-loaded DOJR was investigated batch wise. The effects of varying parameters such as $\mathrm{pH}$ and initial fluoride concentration for the removal of fluoride from water were investigated using both the adsorbents.

\section{MATERIALS AND METHODS}

\section{Chemicals and instrumentation}

The stock solution of fluoride was prepared from $\mathrm{NaF}$ purchased from Wako Chemical Co. Ltd. Japan. The $\mathrm{CeCl}_{3} \cdot 7 \mathrm{H}_{2} \mathrm{O}$ purchased from Wako Chemical and $\mathrm{CeSO}_{4} \cdot 4 \mathrm{H}_{2} \mathrm{O}$ purchased from Sigma Aldrich were used to prepare $\mathrm{Ce}(\mathrm{III})$ and $\mathrm{Ce}(\mathrm{IV})$ solution, respectively, for loading reaction. The $\mathrm{pH}$ of the solution was measured using $\mathrm{pH}$ meter (TOA DKK, HM-30R pH meter). The surface structure of DOJR before and after $\mathrm{Ce}$ (III) loading was analysed by using electron microscope. An elemental 
analysis of DOJR before and after Ce(IV) loading were performed by using an Energy Dispersive X-ray spectrometer (Shimadzu model, EDX-800HS). The concentration of metal ion was measured by an inductively coupled plasma atomic emission spectrometer (ICP-AES, Shimadzu model ICPS 8100) where as that of fluoride was analyzed by ion chromatography (Dionex model ICS 1500).

\section{Preparation of cerium loaded DOJR}

The chemical modification of DOJR was carried out according to the procedure described elsewhere (Paudyal et al. 2012). In the present study, three grams of DOJR was mixed with $500 \mathrm{~mL}$ of $0.1 \mathrm{M} \mathrm{Ce}(\mathrm{III})$ solution at $\mathrm{pH}$ around 3.4 and shacked for $24 \mathrm{~h}$ at $30{ }^{\circ} \mathrm{C}$ for the immobilization of $\mathrm{Ce}(\mathrm{III})$ ion instead of $\mathrm{Zr}$ (IV). Then it was washed with distilled water until neutral $\mathrm{pH}$ was achieved and was dried in convection oven at $70{ }^{\circ} \mathrm{C}$ for two days. The material prepared was termed as $\mathrm{Ce}$ (III) loaded DOJR (i.e., Ce(III)-DOJR) hereafter. Similarly, $\mathrm{Ce}(\mathrm{IV})$ sulphate solution was used in order to prepare the $\mathrm{Ce}(\mathrm{IV})$ loaded DOJR (Ce(IV)-DOJR). During the loading reaction, $\mathrm{Ca}^{2+}$ ions present in the dried orange juice residue (DOJR) undergoes cation exchange reaction with the loaded $\mathrm{Ce}(\mathrm{III})$ or $\mathrm{Ce}(\mathrm{IV})$ ions and the coordinated hydroxyl group present in both types of cerium loaded DOJR were expected to be substituted with fluoride during adsorption also shown in Scheme 1.

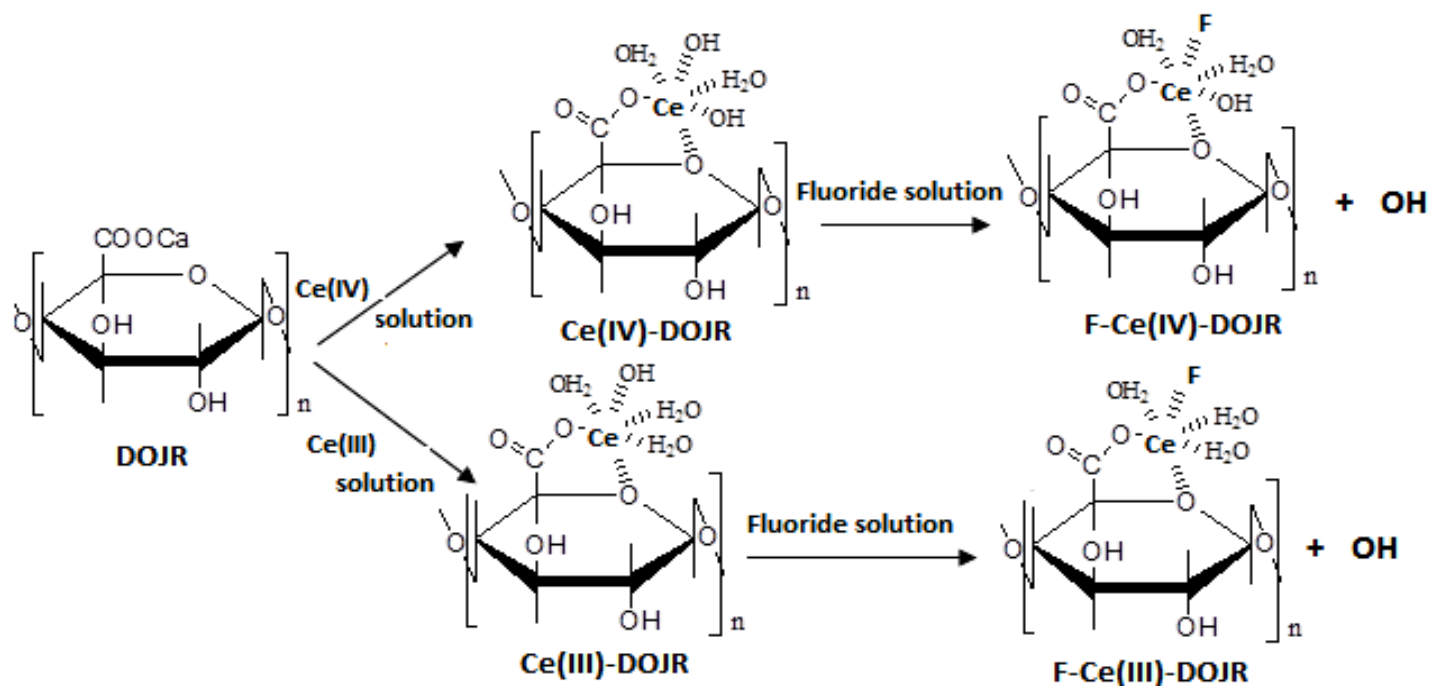

Scheme 1. Plausible mechanism for the loading of cerium onto DOJR and ligand substitution during fluoride adsorption

\section{Batch adsorption studies}

The adsorption experiments for cerium loaded DOJR towards fluoride ion was carried out at varying $\mathrm{pH}$ (1.5 to $11.5)$, contact time and fluoride ions concentration using batch adsorption method. In a typical adsorption experiment, $10 \mathrm{mg}$ adsorbent and $15 \mathrm{~mL}$ of fluoride solution were mixed in sealed glass bottle and shaken for $24 \mathrm{~h}$ at $30{ }^{\circ} \mathrm{C}$. The solid-liquid mixture was separated by filtration and the filtrate was analyzed using ion chromatography. The adsorption percentage and capacity were evaluated by using following relationship

$$
\begin{gathered}
\% A=\frac{C_{i}-C_{e}}{C_{i}} \times 100 \\
q=\frac{C_{i}-C_{e}}{W} \times V
\end{gathered}
$$

Where, $C_{i}$ and $C_{e}$ are initial and equilibrium concentration $(\mathrm{mmol} / \mathrm{L})$ respectively. $\mathrm{W}$ is weight of the adsorbent $(\mathrm{g})$ and $\mathrm{V}$ is volume of solution (L).

\section{RESULTS AND DISCUSSION}

\section{Elemental analysis of DOJR}

For the qualitative determination of the presence of various elements in the tested sample of adsorbents, an energy dispersive X-ray spectroscopic (EDX) technique was used. The EDX spectra of DOJR and DOJR after $\mathrm{Ce}(\mathrm{IV})$ loading is presented in Figs 1(a) and 1(b). It was observed from the EDX spectra of DOJR that it contained the elemental peaks of $\mathrm{C}(0.28 \mathrm{keV}), \mathrm{O}(0.32 \mathrm{keV}), \mathrm{Na}$ (1.09 keV), Si (1.78), P (2.04 keV), S (2.32 keV), K (2.89 $\mathrm{keV}), \mathrm{Ca}(3.68$ and $4.12 \mathrm{keV})$ and $\mathrm{Fe}(6.41 \mathrm{keV})$ as shown in Fig. 1(a). After Ce(IV) loading, new peaks corresponding to cerium element were also observed at the energy value of $4.29,4.81,5.24,5.62,6.01$ and 6.27 $\mathrm{keV}$ in addition to the peaks of DOJR as shown in Fig. 1(b) which strongly suggest the effective loading of Ce(IV) onto DOJR.

In addition to this, the intensity of elemental peaks of $\mathrm{Ca}$ at $3.68 \mathrm{keV}$ and $4.12 \mathrm{keV}$ were decreased sharply after $\mathrm{Ce}(\mathrm{IV})$ loading. The peaks corresponds to $\mathrm{Fe}$ at energy 
value around $6.41 \mathrm{keV}$ had nearly disappeared in $\mathrm{Ce}(\mathrm{IV})$ loaded DOJR as shown in Fig. 1(b). These results strongly suggested that, the metal substitution reaction of $\mathrm{Ca}$ and $\mathrm{Fe}$ occurred with $\mathrm{Ce}$ during cerium loading reaction via cation exchange mechanism as demonstrated in Scheme 1.

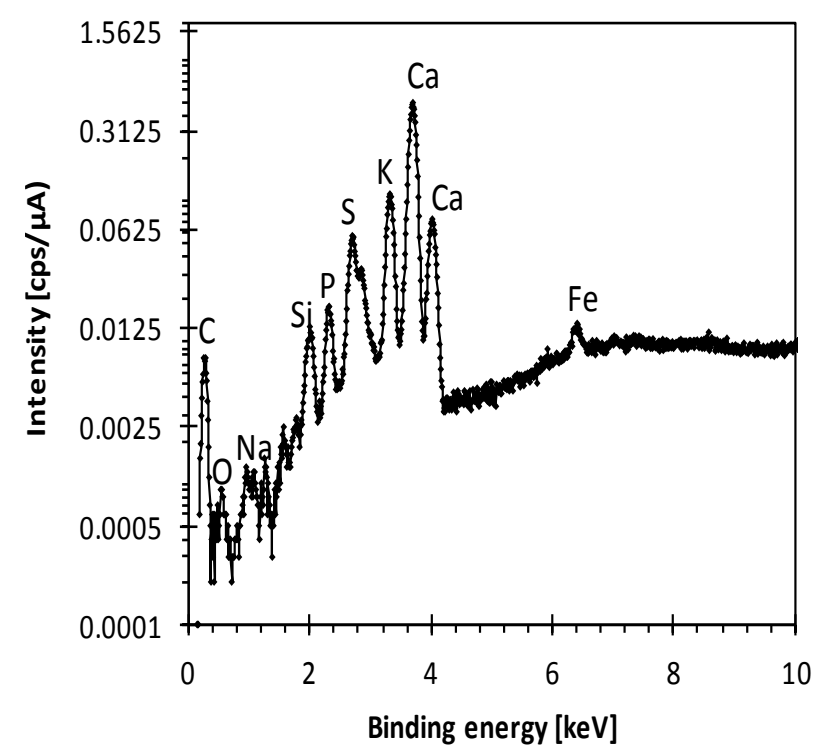

(a)

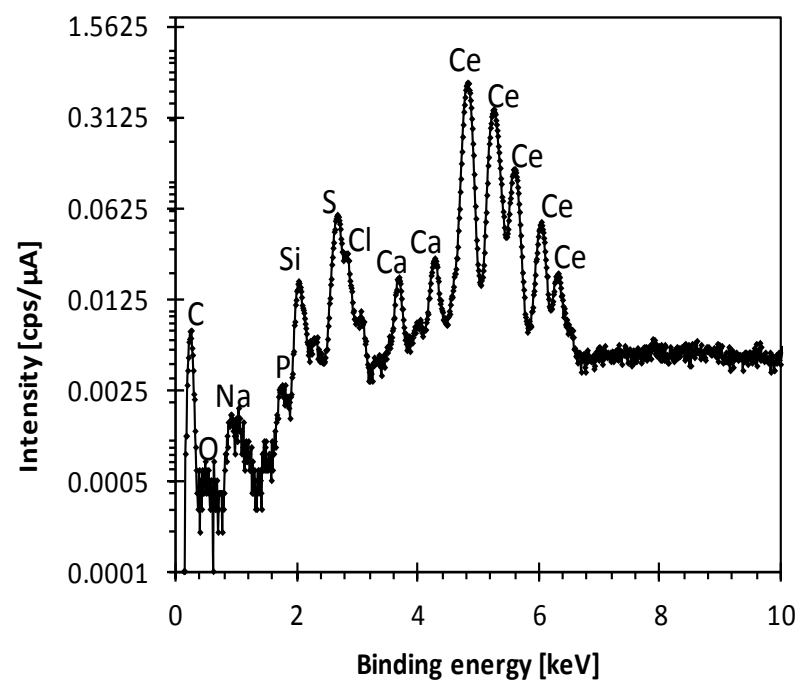

(b)

Fig. 1. An energy dispersive X-ray (EDX) spectra of (a) dried orange juice residue (DOJR) and (b) $\mathrm{Ce}(\mathrm{IV})$ DOJR

\section{Surface analysis of DOJR and Ce(III)-DOJR}

The morphological microstructures and surface characteristics of DOJR and Ce(III)-DOJR were observed with electron microscope as shown in Figs 2(a) and 2(b), respectively. The surface morphology of DOJR had a smooth, golden yellow appearance with low microporosity as shown in Fig. 2(a), while on the surfaces of $\mathrm{Ce}$ (III)-DOJR some irregular cracks or deformation were visible due to chemical modification and removal of low molecular weight water soluble sugar, citric acid and limonene compounds from DOJRas shown in Fig. 2(b). In addition, the observation of the yellow colour pigment on DOJR was due to the presence of limonene compounds, which potentially hindered the metal loading reaction.

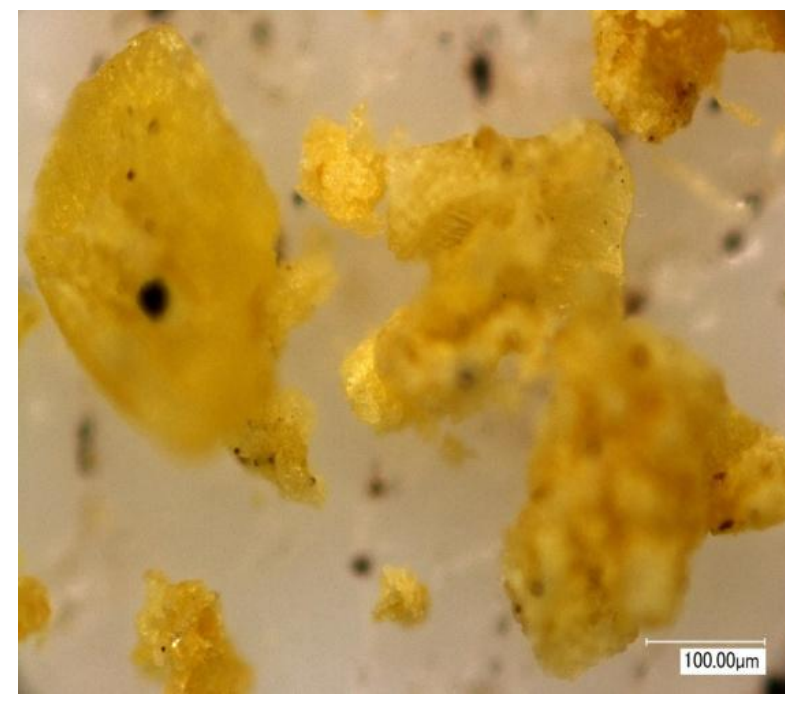

(a)

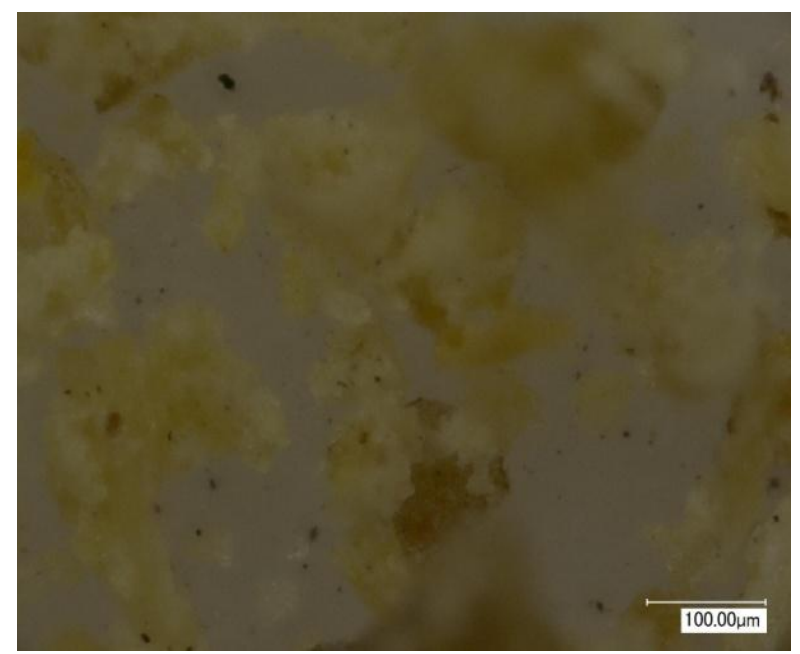

(b)

Fig. 2. Electron microscopic image of (a) dried orange juice residue (DOJR) and (b) Ce(III)-loaded DOJR

\section{Effect of pH solution}

The $\mathrm{pH}$ of the solution strongly affects the surface charge of the adsorbents and the degree of ionization thus it is one of the controlling factors in the process of adsorption. The removal efficiency of fluoride onto $\mathrm{Ce}$ (III)- and Ce(IV)-loaded DOJR is shown in Fig. 3. As shown in Fig. 3 , removal efficiency of fluoride increased up to $94.1 \%$ and $87.7 \%$ by $\mathrm{Ce}(\mathrm{IV})-$ and $\mathrm{Ce}$ (III) loaded DOJR, respectively when $\mathrm{pH}$ was 4 . At $\mathrm{pH}>5.0$ and $\mathrm{pH}<2$, adsorption percentage was noticed to be decreased. The 
decrease in fluoride adsorption at $\mathrm{pH}>5$ was due to the competition of hydroxide ion for the active sites because hydroxide ion concentration was increased with the raise of $\mathrm{pH}$ of the solution. At lower $\mathrm{pH}$ below 3, some fraction of fluoride ions was present in the form of $\mathrm{HF}$, which was difficult to be adsorbed onto the anion exchange site of metal loaded DOJR that potentially caused the decrease of fluoride adsorption percentage. The adsorption mechanism of fluoride onto both the cerium loaded DOJR is explains as follows. The coordinated hydroxyl ions in cerium loaded DOJR were protonated at $\mathrm{pH}$ around 4 to give positively charged surface (reaction a) where negatively charged fluoride ions were interacted and adsorbed with the loss of water molecule (reaction $b$ ). The overall reaction indicated the exchange of coordinated hydroxyl ions present in cerium loaded DOJR with fluoride ion from aqueous solution.

$$
\begin{aligned}
& \equiv \mathbf{C e}-\mathrm{OH}+\mathrm{H}^{+} \rightarrow \equiv \mathbf{C e}-\mathrm{OH}_{2}{ }^{+} \\
& \equiv \mathrm{Ce}-\mathrm{OH}_{2}{ }^{+}+\mathrm{F}^{-} \rightarrow \equiv \mathrm{Ce}-\mathrm{F}+\mathrm{H}_{2} \mathrm{O}
\end{aligned}
$$

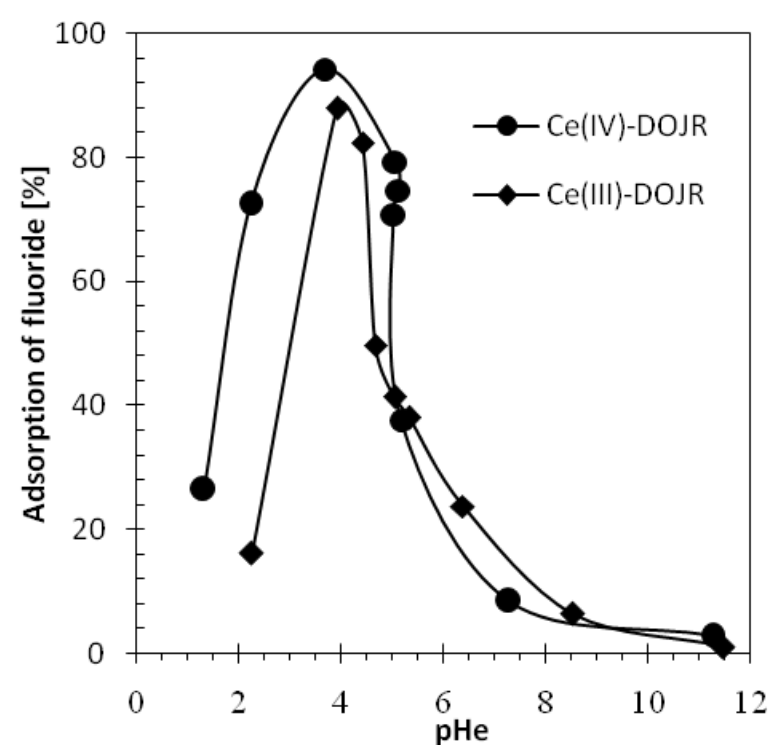

Fig. 3. Effect of pH on the adsorption of fluoride using $\mathrm{Ce}(\mathrm{III})$ and $\mathrm{Ce}(\mathrm{IV})$ loaded DOJR (condition: volume of solution $=10 \mathrm{~mL}$, weight of adsorbent $=10 \mathrm{mg}$, fluoride $=0.5 \mathrm{mmol} / \mathrm{L}, \mathrm{pH}=4$, shaking $=24 \mathrm{~h}$ at $30^{\circ} \mathrm{C}$ )

\section{Adsorption isotherm study}

Fig. 4 shows the adsorption isotherms of fluoride onto $\mathrm{Ce}(\mathrm{III})$ - and $\mathrm{Ce}(\mathrm{IV})$ - loaded DOJR from aqueous medium. It is clear from this figure that adsorption capacity of both the adsorbents increased sharply at lower concentration whereas it was ascribed to attain plateau value at higher concentration. Moreover, compared to Ce(III)-DOJR, Ce(IV)-DOJR had relatively high adsorption capability for fluoride ion. The hydroxyl ligand generated on the co-ordination sphere of loaded cerium in both the adsorbent undergoes ligand exchange reaction between hydroxyl ligands and anionic species of fluoride ion as shown in Scheme 1. A similar type of removal mechanism was observed by Paudyal et al. (2018) and Biswas et al. (2009) for the removal of fluoride ion, respectively, from $\mathrm{Zr}$ (IV) loaded SRP and $\mathrm{Fe}(\mathrm{III})-\mathrm{Sn}$ (IV) bi-metallic oxide adsorbents. Because of high oxidation state of $\mathrm{Ce}$ (IV) followed by $\mathrm{Ce}$ (III), more active sites for fluoride ion were created in Ce(IV)-DOJR and hence adsorption capability of $\mathrm{Ce}(\mathrm{IV})-\mathrm{DOJR}$ was found to be higher than Ce(III)-DOJR.

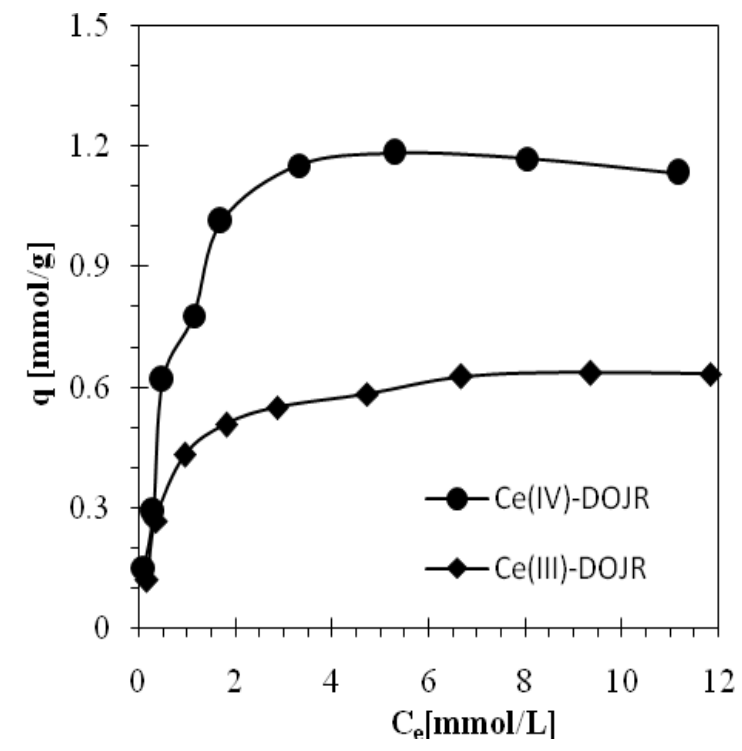

Fig. 4. Adsorption isotherm of cerium loaded DOJR for fluoride ion

The experimental data were modeled by using well known Freundlich and Langmuir isotherm model. The linear form of the Freundlich isotherm model is represented by the equation 3 as (Freundlich 1906).

$\log \mathrm{q}_{\mathrm{e}}=\log \mathrm{K}_{\mathrm{F}}+(1 / \mathrm{n}) \log \mathrm{C}_{\mathrm{e}}$

Where, $\mathrm{K}_{\mathrm{F}}$ and $\mathrm{n}$ are Freundlich constant related to adsorption capacity and adsorption intensity of the adsorbent, respectively. The values of $K_{F}$ and $1 / n$ were estimated from the intercept and slope, respectively, of the linear plot of experimental data of $\log Q_{e}$ vs $\log C_{e}$ as shown in Fig. 5(a).

Similarly, a linear form of the Langmuir isotherm model is given by the equation 4 as (Langmuir 1916).

$$
\frac{C_{e}}{q_{e}}=\frac{1}{q_{\max } b}+\frac{C_{e}}{q_{\max }}
$$

Where, $\mathrm{C}_{\mathrm{e}}(\mathrm{mmol} / \mathrm{L})$ and $\mathrm{q}_{\mathrm{e}}(\mathrm{mmol} / \mathrm{g})$ are equilibrium concentration and amount of adsorption, respectively, while $\mathrm{q}_{\max }$ and $\mathrm{b}$ are maximum loading capacity and adsorption equilibrium constant. The values of $\mathrm{q}_{\mathrm{m}}$ and $\mathrm{b}$ were evaluated from the slope and intercept of straight line plot of $\mathrm{C}_{\mathrm{e}} / \mathrm{q}_{\mathrm{e}}$ versus $C_{e}$ as shown in Fig. 5(b). 

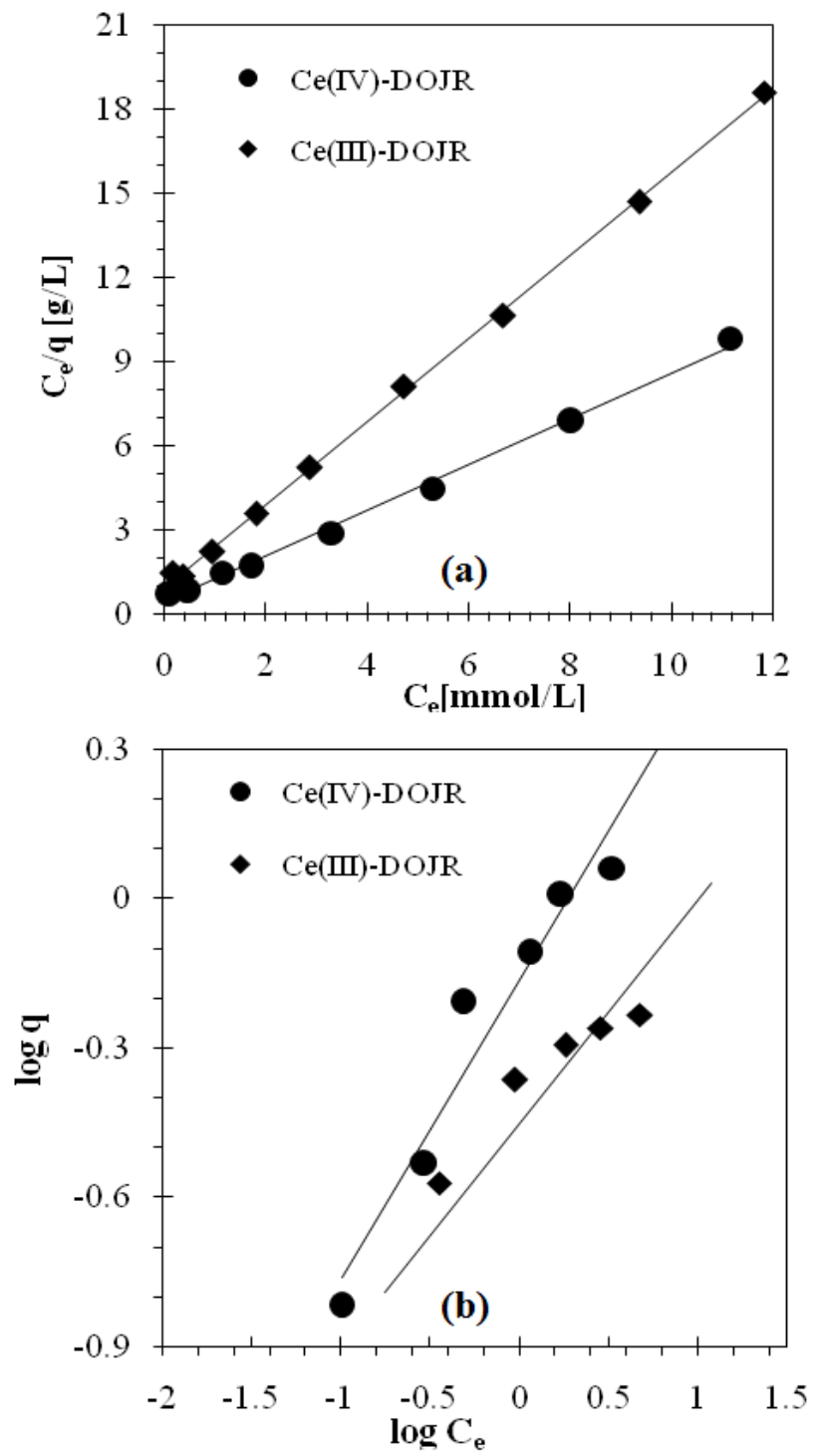

Fig. 5. Modeling of isotherm data using (a) Langmuir and (b) Freundlich adsorption isotherms

The calculated values of Langmuir and Freundlich isotherm constants are listed in Table 1. Although total amount of cerium content in Ce(III)-DOJR $(0.91 \mathrm{mmol} / \mathrm{g})$ and Ce(IV)-DOJR (0.89 $\mathrm{mmol} / \mathrm{g})$ were nearly the same, adsorption potential of fluoride using Ce(IV)-DOJR was higher than $\mathrm{Ce}$ (III)-DOJR which was due to the development of more anion exchange site in $\mathrm{Ce}(\mathrm{IV})$ DOJR owed to higher oxidation state of Ce(IV). Because of the higher value of correlation coefficient obtained for Langmuir isotherm model $\left(\mathrm{R}^{2}>0.99\right)$ than Freundlich isotherm model $\left(\mathrm{R}^{2}\right.$ not higher than 0.93$)$, the Langmuir isotherm model is more suitable to describe adsorptions behavior of fluoride ion onto both the adsorbents tested. Therefore, Langmuir type monolayer formation of fluoride on the surface of both the adsorbents took place during adsorption process.
Table 1. Langmuir and Freundlich parameters for the adsorption of fluoride using cerium loaded DOJR

\begin{tabular}{|l|l|c|c|}
\hline & $\begin{array}{l}\text { Isotherm } \\
\text { Parameters }\end{array}$ & $\begin{array}{c}\text { Ce(III)- } \\
\text { DOJR }\end{array}$ & $\begin{array}{c}\text { Ce(IV)- } \\
\text { DOJR }\end{array}$ \\
\hline Freundlich & $\mathrm{K}_{\mathrm{F}}(\mathrm{mmol} / \mathrm{g})$ & 0.64 & 0.85 \\
& $1 / \mathrm{n}$ & 0.45 & 0.60 \\
& $\mathrm{R}^{2}$ & 0.88 & 0.93 \\
\hline Langmuir & $\mathrm{q}_{\max }(\mathrm{mmol} / \mathrm{g})$ & 0.67 & 1.22 \\
& $\mathrm{~b}(\mathrm{~L} / \mathrm{mmoL})$ & 1.60 & 1.80 \\
& $\mathrm{R}^{2}$ & 0.99 & 0.99 \\
\hline
\end{tabular}

Effect of fluoride ion and $\mathrm{pH}$ for adsorbent stability

The stability of investigated adsorbent is very important for the application purpose. The XRD spectra of Ce(IV)DOJR at two different condition, that is, first after treating low concentration of fluoride at optimal $\mathrm{pH}$ and second after treating high concentration of fluoride at lower $\mathrm{pH}$ were recorded to investigate the adsorbent stability and the results are shown in Figs 6(a) and 6(b), respectively.
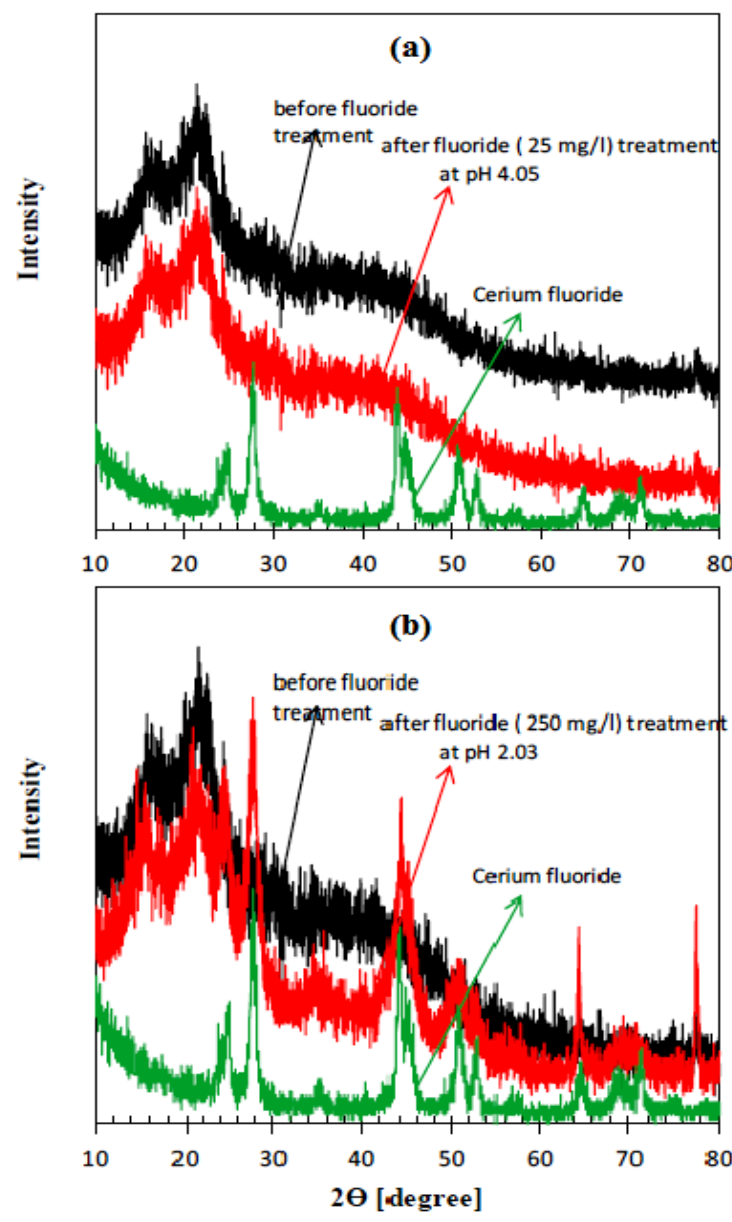

Fig. 6. XRD spectra of (a) Ce(IV)-DOJR before and after treating low concentration of fluoride (25 $\mathrm{mg} / \mathrm{L}$ ) at $4.05 \mathrm{pH}$ and (b) Ce(IV)-DOJR before and after treating high concentration of fluoride $(250$ $\mathrm{mg} / \mathrm{L}$ ) at $2.03 \mathrm{pH}$ 
In the case of using low concentration of fluoride ion as shown in Fig. 6(a), there was no change in XRD spectrum before and after fluoride adsorption indicating that $\mathrm{Ce}(\mathrm{IV})-\mathrm{DOJR}$ is stable and robust if we use for the treatment of trace concentration of fluoride ion. However, in case of using high concentration of fluoride at low $\mathrm{pH}$ as shown in Fig. 6(b), new peaks were observed at $2 \theta$ value at around $24.9,27.6,43.8,50.7,52.6,64.8$ and 71.4 in the XRD spectrum after fluoride treatment. These peaks were exactly in the same position as observed in the case of pure cerium fluoride purchased from Wako Chemical Co. Ltd. Japan. There was high possibility of combining $\mathrm{Ce}(\mathrm{IV})$ leaked at low $\mathrm{pH}$ with fluoride ions to form cerium fluoride precipitate which was evidenced from the observation of crystalline peaks of cerium fluoride in the XRD spectrum of Ce(IV)-DOJR obtained after the treatment with high concentration of fluoride at strongly acidic $\mathrm{pH}$ as depicted in Fig. 6.b.

\section{CONCLUSION}

In this study, two types of cerium loaded DOJR were successfully developed for fluoride ion adsorption by loading $\mathrm{Ce}(\mathrm{III})$ and $\mathrm{Ce}(\mathrm{IV})$ onto DOJR. The optimum $\mathrm{pH}$ for fluoride removal was 4 . The adsorption isotherm was fit better with Langmuir isotherm model than Freundlich model. High concentration of fluoride cause significant leakage of $\mathrm{Ce}(\mathrm{IV})$ at low $\mathrm{pH}$ which was concluded to be combined with fluoride ion to give cerium fluoride precipitate. Adsorption test using trace concentration of fluoride showed negligible leakage of loaded Ce(IV) from Ce(IV)-DOJR, which indicate high stability of this adsorbent at this condition. Therefore, it is expected that the Ce(IV)-DOJR investigated in this study can be effective for the treatment of water polluted with trace amount of fluoride ion.

\section{REFERENCES}

Biswas, K., Gupta, K. and Ghos, U.C. 2009. Adsorption of fluoride by hydrous $\mathrm{Fe}(\mathrm{III})-\mathrm{Sn}(\mathrm{IV})$ bi-metal oxide from aqueous solution. Chemical Engineering Journal 149:196-206.

Freundlich, H. 1906. Uber die adsorption in losungen. Journal of Physical Chemistry 57: 385-470.

Langmuir, I. 1916. The constitution and fundamental properties of solids and liquids. Journal of American Chemical Society 38: 2221-2295.
Liao, X.P. and Shi, B. 2005. Adsorption of fluoride on $\mathrm{Zr}(\mathrm{IV})$-impregnated collagen fiber. Environmental Science and Technology 39: 4628-4632.

Meenakshi, S. and Viswanathan, N. 2007. Identification of selective ion exchange resin for fluoride adsorption. Journal of Colloid and Interface Science 308: 438-350.

Paudyal, H., Inoue, K., Kawakita, H., Ohto, K., Kamata, H. and Alam, S. 2018. Removal of fluoride by effectively using spent resin powder. Journal of Material Cycles and Waste Management 20(2): 975984.

Paudyal, H., Pangeni, B., Inoue, I., Kawakita, H., Ohto, K., Ghimire, K.N. and Alam, S. 2013. Preparation of novel alginate based anion exchanger from Ulva japonica and its application for the removal of trace concentration of fluoride from water. Bioresource Technology 148: 221-227.

Paudyal, H., Pangeni, B., Inoue, K., Kawakita, H., Ohto, K., Harada, H. and Alam, A. 2011. Adsorptive removal of fluoride from aqueous solution using orange waste loaded with multi-valent metal ions. Journal of Hazardous Materials 192: 676-682.

Paudyal, H., Pangeni, B., Inoue, K., Matsuada, M., Suzuki, R., Kawakita, H., Ohto, K., Biswas, B.K. and Alam, S. 2012. Adsorptive behavior of fluoride ion on $\mathrm{Zr}(\mathrm{IV})$ loaded orange waste gel from aqueous solution. Separation Science and Technology 47: 96103.

Shen, F., Chen, X., Gao, P. and Chen, G. 2003. Electrochemical removal of fluoride ions from industrial wastewater. Chemical Engineering Science 58: 987-993.

Viswanathan, N. and Meenakshi, S. 2008. Enhanced fluoride sorption using $\mathrm{La}(\mathrm{III})$ incorporated carboxylated chitosan beads. Journal of Colloid and Interface Science 322: 375-383.

World Health Organization 1993.Guidelines for drinking water quality. WHO guidelines.

Zhao, Y., Li, X., Liu, L. and Chen, F. 2008. Fluoride removal by $\mathrm{Fe}(\mathrm{III})$-loaded ligand exchange cotton cellulose adsorbent from drinking water. Carbohydrate Polymer 72: 144-150. 